\title{
Quantitative anatomy of primary ossification centres of the lateral and basilar parts of the occipital bone in the human foetus
}

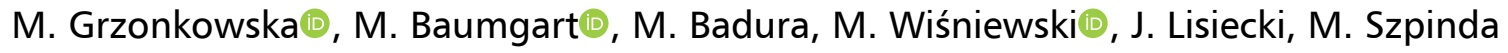 \\ Department of Normal Anatomy, the Ludwik Rydygier Collegium Medicum in Bydgoszcz, \\ the Nicolaus Copernicus University in Torun, Poland
}

[Received: 28 September 2021; Accepted: 6 October 2021; Early publication date: 5 November 2021]

Background: Computed tomography (CT)-based quantitative analysis of primary ossification centres in the cranium has not been carried out to date due to the limited availability of the foetal human material. Detailed morphometric data about the development of primary ossification centres in human foetuses may be useful in the early detection of developmental defects. Understanding the growth and development of the occipital bone is crucial in assessing the normal and pathological development of the cranial base, and the cranium as a whole. Materials and methods: The study material comprised 37 human foetuses (16 males and 21 females) aged 18-30 weeks of gestation. Using CT, digital image analysis software, three-dimensional reconstruction and statistical methods, the size of the primary ossification centres of the lateral and basilar parts of the occipital bone was evaluated.

Results: The morphometric characteristics of primary ossification centres of the lateral and basilar parts of the occipital bone display neither sex nor laterality differences. These ossification centres grow linearly with respect to their sagittal and transverse diameters, projection surface area and volume.

Conclusions: The obtained morphometric data of primary ossification centres in the lateral and basilar parts of the occipital bone may be considered as normative for their respective prenatal weeks and may contribute to the estimation of gestational ages and the diagnostics of congenital defects. (Folia Morphol 2021; 80, 4: 895-903)

Key words: occipital bone, bone development, osteogenesis, foetal development

\section{INTRODUCTION}

The development and ossification of the cranium is divisible into a slower and relatively stable growth of the cranial base and a considerably faster growth of the calvaria. The growth and formation of the cranial base has a major impact on the development of the brain and the final appearance of the facial skeleton. Ossification within the cranial base starts with the occipital bone and progresses anteriorly, delimiting the calvaria from the facial skeleton [9].

The occipital bone is made up of five components positioned around the foramen magnum, i.e. the 
basilar part anteriorly, the two lateral parts on both sides, and the lower or supraoccipital and the upper or interparietal parts of the squamous part posteriorly $[2,10]$. The basilar, lateral and supraoccipital parts of the occipital bone surround the foramen magnum and ossify in an endochondral manner, while the interparietal part presents intramembranous ossification. The basilar part of the occipital bone develops from two parachordal or basioccipital cartilages that are derivatives of the middles of all occipital somites [1-4]. The lateral parts of the occipital bone develop from two exoccipital cartilages, while the inferior part of the squamous part of occipital bone develops from two supraoccipital cartilages.

The ossification of the occipital bone begins as early as at 8 weeks of gestational age in the following order: lower part of its squamous part, upper part of its squamous part, and finally its lateral parts. At 11 weeks of gestational age, ossification also includes the basilar part of the occipital bone [8].

In the newborn, the occipital bone consists of four independent parts. Fusion of the squamous part with the lateral parts occurs between 1 and 4 years of age, while fusion of the basilar part with the lateral parts progresses between 3 and 6 years of age [2].

The timing of ossification of particular cranial bones is relatively well-known. However, no morphometric data concerning primary ossification centres of the occipital bone has been reported owing to the limited availability of the foetal material [8].

The present paper is the first report in the professional literature to focus on the morphometric analysis of the primary ossification centres in the lateral and basilar parts of the occipital bone in human foetuses with the use of computed tomography (CT) imaging.

Detailed morphometric data on the development of ossification centres in human foetuses may be useful in the early detection of developmental defects. Understanding the growth and development of the occipital bone is crucial in assessing the normal and abnormal development of the cranial base. Abnormalities of the occipital bone development may involve stenosis of the foramen magnum in thanatoforic dysplasia, malformations in anencephaly, or shallowing of the posterior cranial fossa typical of Chiari malformation [7].

In the present study we aimed:

- to determine normative values for linear, planar and volumetric parameters of the primary ossifi- cation centres of the lateral and basilar parts of the occipital bone in human foetuses;

- to examine possible sex differences for all analysed parameters;

- to compute growth dynamics for the analysed parameters, expressed by best-matched mathematical models.

\section{MATERIALS AND METHODS}

The study material comprised 37 human foetuses (16 males and 21 females) aged 18 to 30 weeks of gestation, originating from spontaneous miscarriages and preterm deliveries. The foetuses were collected before the year 2000 and still remain part of the foetal collection of the Department of Normal Anatomy. The experiment was approved by the Bioethics Committee of the Ludwik Rydygier Collegium Medicum in Bydgoszcz (KB 275/2011). The inclusion criteria of the foetuses were based on the evaluation of their explicit morphology and statistical cards with the course of pregnancy. Since on macroscopic examination, neither internal nor external conspicuous morphological malformations were found, all included specimens were identified as normal. Of note, the foetuses did not display any developmental abnormalities of the musculoskeletal system. Foetal ages were determined based on the crown-rump length (CRL) and the known date of the beginning of the last maternal menstrual period. Furthermore, the investigated foetuses could not suffer from growth retardation, as the correlation between the gestational age based on the CRL and that calculated by the last menstruation reached $R=0.98(p<0.001)$. Table 1 lists the characteristics of the study group, including the age, number and sex of the foetuses.

Using the Siemens-Biograph $128 \mathrm{mCT}$ scanner (Siemens Healthcare GmbH, Erlangen, Germany) located in the Department of Positron Emission Tomography and Molecular Imaging (Oncology Centre, the Ludwik Rydygier Collegium Medicum in Bydgoszcz, the Nicolaus Copernicus University Bydgoszcz, Poland), scans of foetuses in DICOM format were acquired at $0.4 \mathrm{~mm}$ intervals (Fig. 1). The grey scale of the obtained CT images expressed in Hounsfield units (HU) varied from -275 to -134 for minimum, and from +1165 to +1558 for maximum. Therefore, the window width (WW) varied from 1.404 to 1.692 , and the window level (WL) varied from +463 to +712 . The specifics of the imaging protocol were as 
Table 1. Age, number and sex of the foetuses studied

\begin{tabular}{|c|c|c|c|c|c|c|c|}
\hline \multirow[t]{2}{*}{ Gestational age } & \multicolumn{4}{|c|}{ Crown-rump length [mm] of foetuses } & \multirow[t]{2}{*}{ Number } & \multicolumn{2}{|c|}{ Sex } \\
\hline & Mean & SD & Minimum & Maximum & & Male & Female \\
\hline 18 & 133.33 & 5.77 & 130.00 & 140.00 & 3 & 1 & 2 \\
\hline 19 & 146.50 & 2.89 & 143.00 & 150.00 & 4 & 2 & 2 \\
\hline 20 & 161.00 & 2.71 & 159.00 & 165.00 & 4 & 2 & 2 \\
\hline 21 & 173.67 & 2.31 & 171.00 & 175.00 & 3 & 2 & 1 \\
\hline 22 & 184.67 & 1.53 & 183.00 & 186.00 & 3 & 1 & 2 \\
\hline 23 & 198.67 & 2.89 & 197.00 & 202.00 & 3 & 1 & 2 \\
\hline 24 & 208.00 & 3.56 & 205.00 & 213.00 & 4 & 1 & 3 \\
\hline 25 & 214.00 & & 214.00 & 214.00 & 1 & 0 & 1 \\
\hline 26 & 229.00 & 5.66 & 225.00 & 233.00 & 2 & 1 & 1 \\
\hline 27 & 240.33 & 1.15 & 239.00 & 241.00 & 3 & 3 & 0 \\
\hline 28 & 249.50 & 0.71 & 249.00 & 250.00 & 2 & 0 & 2 \\
\hline 29 & 253.00 & 0.00 & 253.00 & 253.00 & 2 & 0 & 2 \\
\hline 30 & 262.67 & 0.58 & 262.00 & 263.00 & 3 & 2 & 1 \\
\hline Total & & & & & 37 & 16 & 21 \\
\hline
\end{tabular}

SD - standard deviation

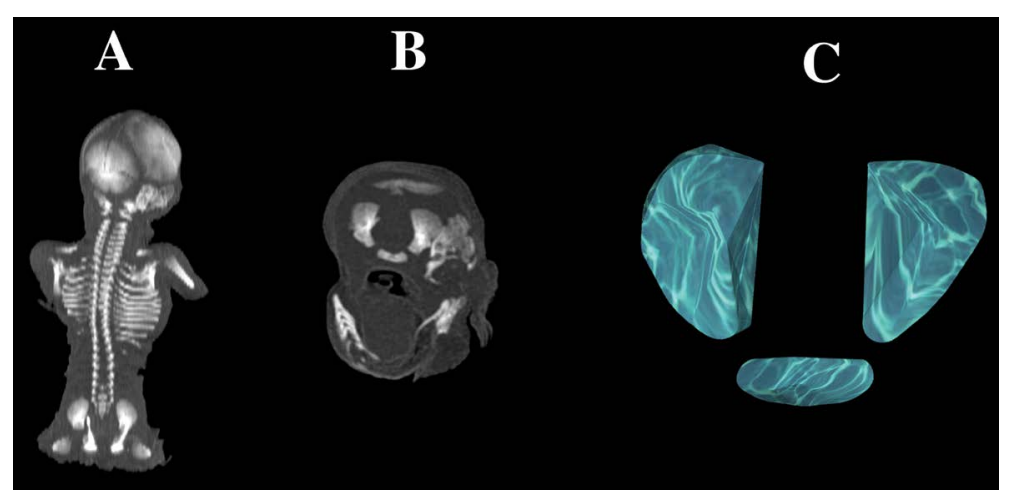

Figure 1. A female human foetus aged 21 weeks in the frontal projection (A), its skeletal reconstruction in the frontal projection (B), three-dimensional reconstruction of ossification centres of the lateral and basilar parts of the occipital bone (C) using 0sirix 3.9 MD.

follows: $\mathrm{mAs}-60, \mathrm{kV}-80$, pitch -0.35 , field of view -180 , rotation time $-0.5 \mathrm{~s}$, while those of the CT data were: slice thickness $-0.4 \mathrm{~mm}$, image increment - $0.6 \mathrm{~mm}$, and kernel - B45 f-medium. Measurements for either lateral part and the basilar part of the occipital bone were conducted in a specific order (Fig. 2). In each foetus, assessment of the linear parameters, projection surface area and volume of primary ossification centres of the lateral and basilar parts of the occipital bone was carried out. Despite the cartilaginous stage of development, a morphometric analysis regarding their sagittal diameter and volume was feasible, as outlines of the entire bone were already evidently visible $[3,4]$.
Measurements of primary ossification centres of the lateral (right and left) and basilar parts of the occipital bone included:

- their sagittal diameter in the lateral (right and left) parts, based on the determined distance between proximal and distal borderlines in the frontal plane (Fig. 2);

- their transverse diameter in the lateral (right and left) parts, based on the determined distance between medial and lateral borderlines in the frontal plane (Fig. 2);

- their transverse diameter in the basilar part, based on the determined distance between medial and lateral borderlines in the frontal plane; 
- their sagittal diameter in the basilar part, based on the determined distance between proximal and distal borderlines in the frontal plane (Fig. 2);

- projection surface area in the lateral (right and left) parts, based on the outlined area occupied by the ossification centre in the frontal plane (Fig. 2);

- projection surface area in the basilar part, based on the outlined area occupied by the ossification centre in the frontal plane (Fig. 2);

- volume, calculated using advanced diagnostic imaging tools for three-dimensional reconstruction, taking into account position and the absorption of radiation by bony tissue (Fig. 1C).

\section{Statistical analysis}

In the present study the Statistica 12.5 and PQStat 1.6.2. programmes were used to analyse all numerical data. Distribution of variables was checked using the Shapiro-Wilk (W) test, while homogeneity of variance was checked using Fisher's test. To compare the means, Student's t test for dependent (left-right) and independent (male-female) variables was used. Afterwards, one-way analysis of variance and Tukey's test were used for post-hoc analysis. If no similarity of variance occurred, the non-parametric Kruskal-Wallis test was used. The characterisation of developmental dynamics of the analysed parameters was based on linear and curvilinear regression analysis. The match between the estimated curves and measurement results was evaluated on the basis of the coefficient of determination $\left(R^{2}\right)$. Differences were considered statistically significant at $p<0.05$. The relationship between variables was also estimated with the Pearson correlation coefficient ( $r$ ).

In an attempt to minimise measurement and observer bias, all measurements were completed by one experienced researcher (M.B.) specialising in image interpretation. Each measurement was reiterated 3 times under the same conditions but at different times, and then averaged. As shown in Table 2, the intra-class correlation coefficients calculated on the basis of an observer were statistically significant $(p<0.01)$ and of excellent reproducibility.

\section{RESULTS}

The mean values and standard deviations of the analysed parameters of primary ossification centre of the lateral parts of the occipital bone are shown in Tables 3 and 4, while those referring to the basilar part of the occipital bone are shown in Table 5 .

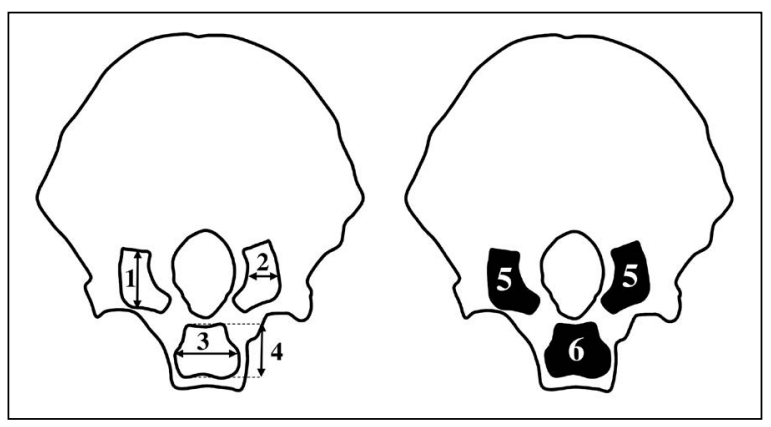

Figure 2. A measurement scheme of ossification centres of the lateral and basilar parts of the occipital bone: 1 - sagittal diameter of the lateral part; 2 - transverse diameter of the lateral part; 3 - transverse diameter of the basilar part; 4 - sagittal diameter of the basilar part; 5 - projection surface area of the lateral part; 6 - projection surface area of the basilar part.

Table 2. Intra-class correlation coefficients (ICC) values for inter-observer recurrence

\begin{tabular}{lc}
\hline Parameter & ICC \\
\hline Right sagittal diameter of the lateral part & $0.996^{*}$ \\
Left sagittal diameter of the lateral part & $0.995^{*}$ \\
Right transverse diameter of the lateral part & $0.997^{*}$ \\
Left transverse diameter of the lateral part & $0.998^{*}$ \\
Transverse diameter of the basilar part & $0.999^{*}$ \\
Sagittal diameter of the basilar part & $0.996^{*}$ \\
Projection surface area of the right lateral part & $0.998^{*}$ \\
Projection surface area of the left lateral part & $0.997^{*}$ \\
Projection surface area of the basilar part & $0.999^{*}$ \\
Volume surface area of the right lateral part & $0.997^{*}$ \\
Volume surface area of the left lateral part & $0.997^{*}$ \\
Volume surface area of the basilar part & $0.998^{*}$ \\
\hline
\end{tabular}

ICC marked with asterisk $\left({ }^{*}\right)$ are statistically significant at $\mathrm{p}<0.0001$

The statistical analysis revealed neither significant sex nor laterality differences, which allowed us to compute one growth curve for each analysed parameter. The developmental dynamics of the sagittal and transverse diameters, projection surface area and volume of the lateral (right and left) parts followed proportionately in reference to gestational age expressed in weeks.

The mean sagittal diameter of the ossification centre of the lateral part of the occipital bone in the gestational age range of 18-30 weeks was between $8.37 \pm 0.17 \mathrm{~mm}$ and $18.74 \pm 1.06 \mathrm{~mm}$ on the right, and between $8.49 \pm 1.05 \mathrm{~mm}$ and $15.36 \pm 1.08 \mathrm{~mm}$ on the left, demonstrating a proportionate growth: $y=-3.714+0.681 \times$ age $\pm 1.346\left(R^{2}=0.79\right)$. 
Table 3. Right and left sagittal and transverse diameters of the lateral part of the occipital ossification centre

\begin{tabular}{|c|c|c|c|c|c|c|c|c|}
\hline \multirow[t]{4}{*}{$\mathbf{N}$} & \multicolumn{8}{|c|}{ Lateral part of the occipital ossification centre } \\
\hline & \multicolumn{4}{|c|}{ Sagittal diameter [mm] } & \multicolumn{4}{|c|}{ Transverse diameter [mm] } \\
\hline & \multicolumn{2}{|c|}{ Right } & \multicolumn{2}{|c|}{ Left } & \multicolumn{2}{|c|}{ Right } & \multicolumn{2}{|c|}{ Left } \\
\hline & Mean & SD & Mean & SD & Mean & SD & Mean & SD \\
\hline 3 & 8.37 & 0.17 & 8.49 & 1.05 & 5.13 & 0.19 & 5.00 & 0.23 \\
\hline 4 & 8.97 & 0.32 & 9.66 & 0.21 & 5.50 & 0.19 & 5.44 & 0.24 \\
\hline 4 & 9.95 & 1.29 & 10.19 & 0.34 & 6.03 & 0.17 & 6.02 & 0.18 \\
\hline 3 & 8.62 & 1.52 & 11.00 & 0.22 & 6.48 & 0.08 & 6.48 & 0.08 \\
\hline 3 & 9.00 & 0.31 & 11.65 & 0.27 & 6.77 & 0.12 & 6.78 & 0.13 \\
\hline 3 & 11.90 & 2.14 & 12.19 & 0.30 & 6.99 & 0.02 & 7.01 & 0.00 \\
\hline 4 & 13.93 & 2.06 & 12.77 & 0.27 & 7.17 & 0.01 & 7.17 & 0.01 \\
\hline 1 & 14.26 & & 13.24 & & 7.41 & & 7.41 & \\
\hline 2 & 13.37 & 1.32 & 13.59 & 0.02 & 7.49 & 0.05 & 7.32 & 0.18 \\
\hline 3 & 15.72 & 1.82 & 13.85 & 0.08 & 7.85 & 0.20 & 7.51 & 0.19 \\
\hline 2 & 14.35 & 0.45 & 14.00 & 0.01 & 8.11 & 0.04 & 7.75 & 0.03 \\
\hline 2 & 17.39 & 1.56 & 14.24 & 0.20 & 8.38 & 0.04 & 8.02 & 0.04 \\
\hline 3 & 18.74 & 1.06 & 15.36 & 1.08 & 8.98 & 0.29 & 8.87 & 0.29 \\
\hline
\end{tabular}

SD — standard deviation

Table 4. Projection surface area and volume of the lateral part of the occipital ossification centre

\begin{tabular}{|c|c|c|c|c|c|c|c|c|c|}
\hline \multirow{4}{*}{$\begin{array}{l}\text { Gestational } \\
\text { age [weeks] }\end{array}$} & \multirow[t]{4}{*}{$\mathbf{N}$} & \multicolumn{8}{|c|}{ Lateral part of the occipital ossification centre } \\
\hline & & \multicolumn{4}{|c|}{ Projection surface area $\left[\mathrm{mm}^{2}\right]$} & \multicolumn{4}{|c|}{ Volume $\left[\mathrm{mm}^{3}\right]$} \\
\hline & & \multicolumn{2}{|c|}{ Right } & \multicolumn{2}{|c|}{ Left } & \multicolumn{2}{|c|}{ Right } & \multicolumn{2}{|c|}{ Left } \\
\hline & & Mean & SD & Mean & SD & Mean & SD & Mean & SD \\
\hline 18 & 3 & 27.95 & 4.20 & 24.04 & 1.28 & 33.82 & 5.08 & 29.09 & 1.55 \\
\hline 19 & 4 & 33.52 & 1.60 & 27.65 & 1.90 & 40.56 & 1.93 & 33.45 & 2.29 \\
\hline 20 & 4 & 39.11 & 2.30 & 33.59 & 4.76 & 47.32 & 2.78 & 40.64 & 5.76 \\
\hline 21 & 3 & 46.02 & 1.75 & 34.84 & 11.02 & 55.69 & 2.12 & 42.15 & 3.33 \\
\hline 22 & 3 & 51.91 & 2.19 & 34.12 & 1.78 & 62.81 & 2.65 & 41.29 & 2.16 \\
\hline 23 & 3 & 55.89 & 1.46 & 49.17 & 1.81 & 67.62 & 1.76 & 59.49 & 1.50 \\
\hline 24 & 4 & 59.79 & 1.33 & 55.94 & 2.31 & 72.35 & 1.60 & 67.68 & 1.06 \\
\hline 25 & 1 & 63.73 & & 75.77 & & 77.11 & & 91.68 & \\
\hline 26 & 2 & 65.95 & 0.47 & 64.35 & 6.97 & 79.80 & 0.57 & 77.86 & 0.54 \\
\hline 27 & 3 & 71.43 & 2.49 & 76.28 & 2.85 & 86.43 & 3.02 & 92.30 & 3.54 \\
\hline 28 & 2 & 75.58 & 0.36 & 83.34 & 0.98 & 91.45 & 0.43 & 100.84 & 1.02 \\
\hline 29 & 2 & 78.99 & 1.00 & 91.02 & 1.07 & 95.58 & 1.21 & 110.14 & 1.49 \\
\hline 30 & 3 & 92.00 & 3.15 & 94.39 & 6.21 & 111.32 & 11.08 & 114.22 & 9.93 \\
\hline
\end{tabular}

SD - standard deviation

The mean transverse diameter of the ossification centre of the lateral part of the occipital bone in the gestational age range of 18-30 weeks increased from $5.13 \pm 0.19 \mathrm{~mm}$ to $8.98 \pm 0.29 \mathrm{~mm}$ on the right, and from $5.00 \pm 0.23 \mathrm{~mm}$ to $8.87 \pm 0.29 \mathrm{~mm}$ on the left, following the linear function: $y=0.412+0.278 \times$ $\times$ age $\pm 0.269\left(R^{2}=0.94\right)$ (Figs. 3A, B).

The mean projection surface area of the ossification centre of the lateral part of the occipital bone ranged from $27.95 \pm 4.20 \mathrm{~mm}^{2}$ at 18 weeks of gestation to 
Table 5. Sagittal and transverse diameters, projection surface area and volume of the basilar part of the occipital ossification centre

\begin{tabular}{|c|c|c|c|c|c|c|c|c|c|}
\hline \multirow{3}{*}{$\begin{array}{l}\text { Gestational } \\
\text { age [weeks] }\end{array}$} & \multirow[t]{3}{*}{$\mathbf{N}$} & \multicolumn{8}{|c|}{ Basilar part of the occipital ossification centre } \\
\hline & & \multicolumn{2}{|c|}{$\begin{array}{c}\text { Sagittal diameter } \\
{[\mathrm{mm}]}\end{array}$} & \multicolumn{2}{|c|}{$\begin{array}{c}\text { Transverse diameter } \\
{[\mathrm{mm}]}\end{array}$} & \multicolumn{2}{|c|}{$\begin{array}{l}\text { Projection surface area } \\
{\left[\mathrm{mm}^{2}\right]}\end{array}$} & \multicolumn{2}{|c|}{$\begin{array}{l}\text { Volume } \\
{\left[\mathrm{mm}^{3}\right]}\end{array}$} \\
\hline & & Mean & SD & Mean & SD & Mean & SD & Mean & SD \\
\hline 18 & 3 & 5.76 & 0.08 & 5.06 & 0.08 & 22.71 & 0.63 & 29.52 & 0.82 \\
\hline 19 & 4 & 5.94 & 0.13 & 5.24 & 0.13 & 24.29 & 1.17 & 31.57 & 1.52 \\
\hline 20 & 4 & 6.21 & 0.10 & 5.51 & 0.10 & 26.67 & 0.90 & 34.67 & 1.17 \\
\hline 21 & 3 & 6.49 & 0.14 & 5.79 & 0.14 & 29.29 & 1.36 & 38.08 & 1.77 \\
\hline 22 & 3 & 6.71 & 0.06 & 6.01 & 0.06 & 31.49 & 0.56 & 40.94 & 0.73 \\
\hline 23 & 3 & 6.86 & 0.03 & 6.16 & 0.03 & 33.00 & 0.31 & 42.89 & 0.40 \\
\hline 24 & 4 & 6.93 & 0.04 & 6.23 & 0.04 & 33.65 & 0.42 & 43.75 & 0.55 \\
\hline 25 & 1 & 6.98 & & 6.28 & & 34.19 & & 44.45 & \\
\hline 26 & 2 & 7.10 & 0.02 & 6.40 & 0.02 & 35.39 & 0.22 & 46.01 & 0.29 \\
\hline 27 & 3 & 7.19 & 0.01 & 6.49 & 0.01 & 36.40 & 0.11 & 47.32 & 0.14 \\
\hline 28 & 2 & 7.21 & 0.01 & 6.51 & 0.01 & 36.56 & 0.08 & 47.52 & 0.10 \\
\hline 29 & 2 & 7.32 & 0.07 & 6.62 & 0.07 & 37.80 & 0.77 & 49.14 & 1.00 \\
\hline 30 & 3 & 7.65 & 0.20 & 6.95 & 0.20 & 41.45 & 2.32 & 53.89 & 3.02 \\
\hline
\end{tabular}

SD — standard deviation
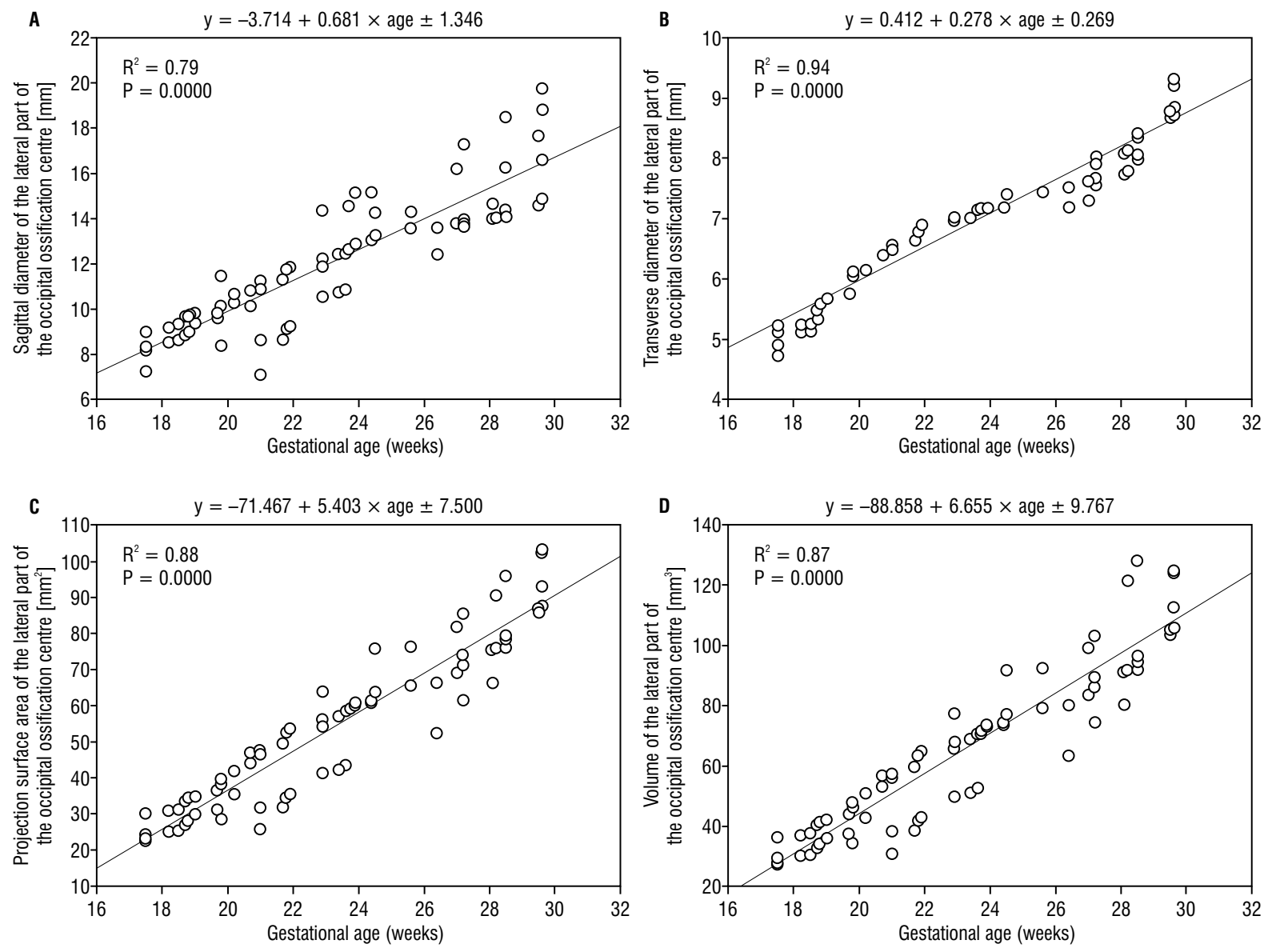

Figure 3. Regression lines for sagittal diameter (A), transverse diameter (B), projection surface area (C) and volume (D) of ossification centres of the lateral parts of the occipital bone. 
A
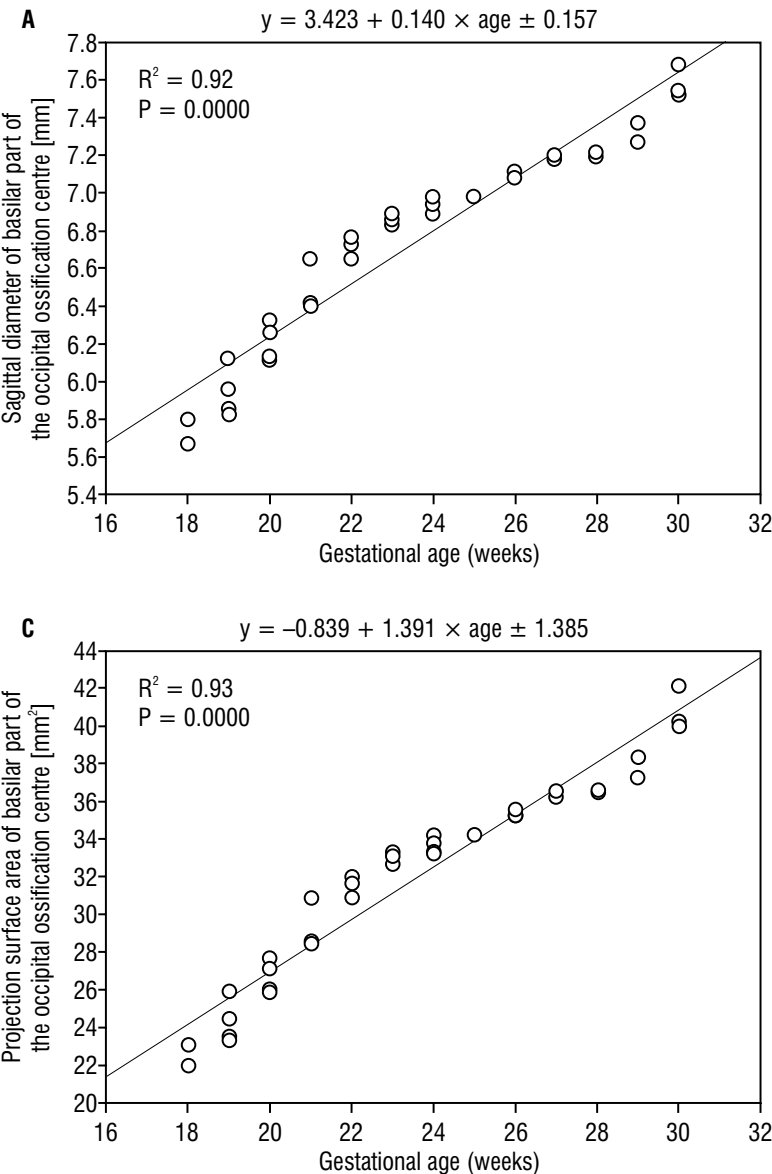

B

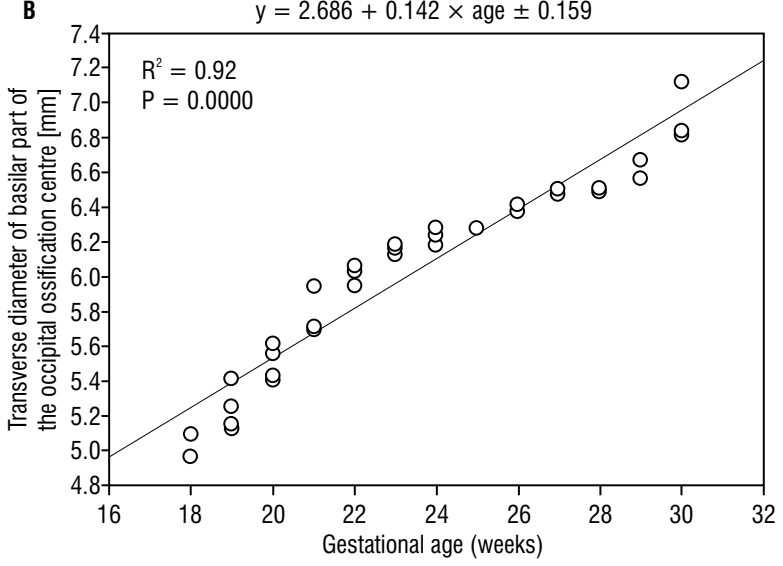

D

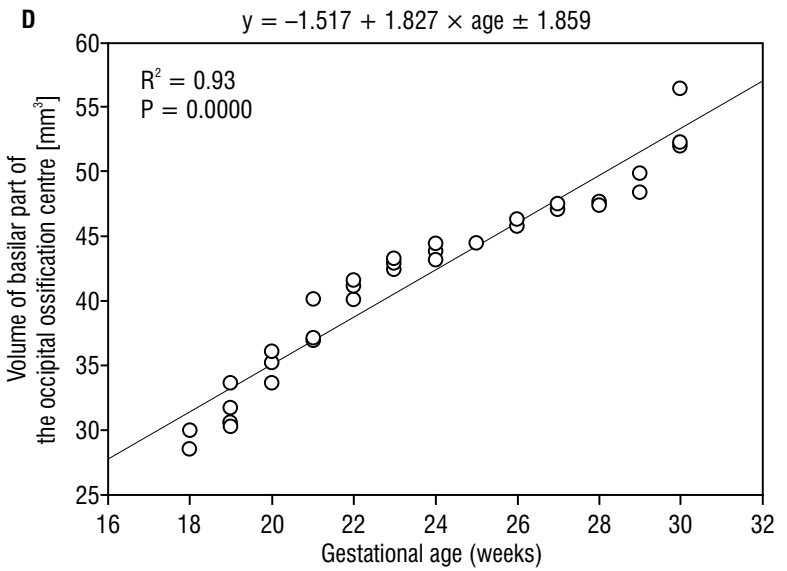

Figure 4. Regression lines for sagittal diameter (A), transverse diameter (B), projection surface area (C) and volume (D) of ossification centre of the basilar part of the occipital bone.

$92.00 \pm 3.15 \mathrm{~mm}^{2}$ at 30 weeks of gestation on the right, and from $24.04 \pm 1.28 \mathrm{~mm}^{2}$ to $94.39 \pm 6.21$ $\mathrm{mm}^{2}$, respectively, on the left, following the function: $y=-71.467+5.403 \times$ age $\pm 7.500\left(R^{2}=0.88\right)$ (Fig. 3C).

The mean volume of the ossification centre of the lateral part of the occipital bone in the gestational age range of 18-30 weeks was between $33.82 \pm$ $\pm 5.08 \mathrm{~mm}^{3}$ and $111.32 \pm 11.08 \mathrm{~mm}^{3}$ on the right, and between $29.09 \pm 1.55 \mathrm{~mm}^{3}$ and $114.22 \pm$ $\pm 9.93 \mathrm{~mm}^{3}$ on the left, in accordance with the function: $y=-88.858+6.655 \times$ age $\pm 9.767\left(R^{2}=0.87\right)$ (Fig. 3D).

The mean sagittal diameter of the ossification centre of the basilar part of the occipital bone in the gestational age range of 18-30 weeks was between $5.76 \pm 0.08 \mathrm{~mm}$ and $7.65 \pm 0.20 \mathrm{~mm}$, demonstrating a proportionate growth: $\mathrm{y}=3.423+0.140 \times$ age \pm $\pm 0.157\left(R^{2}=0.92\right)$ (Fig. 4A).

The mean transverse diameter of the ossification centre of the basilar part of the occipital bone in the gestational age range of 18-30 weeks revealed an increase from $5.06 \pm 0.08$ to $6.95 \pm 0.20 \mathrm{~mm}$, demonstrating a proportionate growth: $\mathrm{y}=2.686+$ $+0.142 \times$ age $\pm 0.159\left(R^{2}=0.92\right)$ (Fig. 4B)

The mean projection surface area of the ossification centre of the basilar part of the occipital bone ranged from $22.71 \pm 0.63 \mathrm{~mm}^{2}$ at 18 weeks to $41.45 \pm 2.32 \mathrm{~mm}^{2}$ at 30 weeks of gestational age, according to the function: $y=-0.839+1.391 \times$ age \pm $\pm 1.385\left(R^{2}=0.93\right)$ (Fig. 4C).

The mean volume of the ossification centre of the basilar part of the occipital bone in the gestational age range of 18-30 grew from $29.52 \pm 0.82 \mathrm{~mm}^{3}$ to $53.89 \pm 3.02 \mathrm{~mm}^{3}$, following the linear model: $y=-1.517+1.827 \times$ age $\pm 1.859\left(R^{2}=0.93\right)($ Fig. 4D) .

\section{DISCUSSION}

Zhang et al. [13] measured the basilar part of the occipital bone in 22 human foetuses aged 15 to 20 weeks of gestation and observed two patterns 
of its ossification in foetuses with a CRL between 115 and $142 \mathrm{~mm}$. In the first pattern found in 7 foetuses, the medial ossification centres of the basilar part of the occipital bone fused into one at an early stage of development. In the second pattern found in 6 foetuses, two medial ossification centres of the basilar part remained separate. The authors measured the length and width of the ossification centres of the basilar part of occipital bone. In foetuses with a CRL corresponding to the period between 17 and 20 weeks of gestational age, the length of the basilar part of the occipital bone was greater than its width. However, between 15 and 17 weeks of gestational age, the width of the basilar part increased faster than its length. The authors concluded that the developmental patterns depend on the developmental stage. The length of the ossification centres in foetuses aged 15 to 20 weeks of gestation ranged from $5.54 \pm 0.07 \mathrm{~mm}$ to $7.83 \pm 0.45 \mathrm{~mm}$, while their width ranged from $3.58 \pm 0.16$ to $5.73 \pm 0.69 \mathrm{~mm}$.

With the use of a digital calliper Badiu et al. [1] measured the vertical and transverse diameters of the basilar and lateral parts of the occipital bone in 19 human foetuses aged 16 to 34 weeks of gestation. They found the vertical diameter of the basilar and lateral parts to increase from 5.54 to $11.14 \mathrm{~mm}$ and from 5.92 to $20.89 \mathrm{~mm}$, respectively. The transverse diameter of the basilar and lateral parts increased from 3.96 to $12.24 \mathrm{~mm}$ and from 2.88 to $12.03 \mathrm{~mm}$, respectively.

The present paper is the first to report morphometric parameters of ossification centres of the lateral and basilar parts of the occipital bone in human foetuses based on computed tomography with their growth models.

The size of the ossification centres in the lateral and basilar parts of the occipital bone followed linear functions of gestational age: $y=-3.714+0.681 \times$ $x$ age \pm 1.346 for sagittal diameter in the lateral parts, $y=0.412+0.278 \times$ age \pm 0.269 for transverse diameter in the lateral parts, $y=-71.467+5.403 \times$ $x$ age \pm 7.500 for projection surface area in the lateral parts, $y=-88.858+6.655 \times$ age \pm 9.767 for volume in the lateral parts, $y=3.423+0.140 \times$ age \pm \pm 0.157 for sagittal diameter in the basilar part, $y=2.686+0.142 \times$ age \pm 0.159 for transverse diameter in the basilar part, $y=-0.839+1.391 \times$ age \pm \pm 1.385 for projection surface area in the basilar part, and $y=-1.517+1.827 \times$ age \pm 1.859 for volume in the basilar part.
In our previous study [6] about the development of the ossification centre of the squamous part of occipital bone in human foetuses, the growth dynamics of the vertical diameter followed the linear functions: $y=-6.462+1.109 \times$ age \pm 0.636 on the right, and $y=-9.395+1.243 \times$ age \pm 0.577 on the left. The transverse diameters of the supraoccipital and interparietal parts as well as projection surface area of the occipital squama ossification centre increased in relation to gestational age expressed in weeks, following the logarithmic functions: $y=-98.232+$ $+39.663 \times \ln ($ age $) \pm 0.721, y=-79.903+32.107 \times$ $\times \ln ($ age $) \pm 0.974, y=-3062.89+1108.98 \times \ln ($ age $) \pm$ \pm 29.476 , respectively. The volume of the occipital squama ossification centre increased in accordance with the quadratic function: $y=-330.105+1.554 \times$ $\times$ age $^{2} \pm 32.559$.

Furthermore, in our study [5] of the development of the frontal squama ossification centre in human foetuses, the growth dynamics of its vertical diameter, projection surface area and volume followed the quadratic functions: $y=13.756+0.021 \times$ age $^{2} \pm$ $\pm 0.024, y=38.285+0.889 \times a^{2} e^{2} \pm 0.034$, and $y=-90.020+1.375 \times$ age $^{2} \pm 11.441$, respectively. However, its transverse diameter increased proportionately to gestational age, as $y=0.956+0.956 \times$ $\times$ age \pm 0.823 .

Regrettably, a lack of reports concerning ossification centres of the lateral and basilar parts of the occipital bone in the medical literature precludes a more detailed discussion on this topic.

Understanding the development of the occipital bone in human foetuses is indispensable for the detection of anomalies of the craniovertebral junction and fractures of the cranial base [10]. The cranial base supports the brain, and many congenital anomalies of the brain correspond to anomalies of the cranial base during development, such as basilar invagination, platybasia, or Chiari malformation [13]. One of such congenital bone defects is atlantooccipital assimilation, a disorder consisting of the presence of bone fusion between the first cervical vertebra and the occipital bone. This fusion is usually incomplete and refers only to the anterior atlantal arch and the anterior edge of the foramen magnum. Atlantooccipital assimilation is often linked to developmental anomalies of the first and second pharyngeal arches. This defect is accompanied by hypoplasia of the occipital bone, reduced clivus length, lack or abnormal formation 
of the atlantooccipital joint, dislocation of the atlantoaxial joint and platybasia. Clinical signs may include an abnormally short neck, reduced cervical spine mobility, abnormal head posture, headache, pain in the neck and upper limbs, scapular elevation, weakness, numbness, dysphagia, dysarthria and torticollis. This anomaly may result in the formation of Chiari syndrome, which represents a group of various developmental disorders whose common feature is reduction of the posterior part of the cranial cavity which does not include the cerebellum or the lower part of the brainstem. Atlantooccipital assimilation may also result in compression or even complete closure of the vertebral artery by the bone canal, leading to dizziness, convulsions, mental disorders or fainting [11, 12].

Another anomaly of the occipital bone is basilar impression - invagination of the edges of the foramen magnum into the cranial cavity, resulting in a reduction of the capacity of the posterior cranial fossa. This invagination often co-exists with syndromes such as Klippel-Feil or Chiari, as well as atlantoaxial dislocations. This defect usually leads to serious neurological disorders and may result in the compression of spinal nerve roots, the spinal cord and brainstem, vascular or respiratory disorders [12].

The main limitation of this study was a relatively narrow gestational age group, ranging from 18 to 30 weeks, and a small number of cases, including 37 human foetuses.

\section{CONCLUSIONS}

The morphometric characteristics of primary ossification centres of the lateral and basilar parts of the occipital bone display neither sex nor laterality differences.

These primary ossification centres grow linearly with respect to their sagittal and transverse diameters, projection surface area, and volume.

The obtained morphometric data of primary ossification centres in the lateral and basilar parts of the occipital bone may be considered as normative for their respective prenatal weeks and may contribute to the estimation of gestational ages and the diagnostics of congenital defects.

\section{Conflict of interest: None declared}

\section{REFERENCES}

1. Badiu GA, Tarța-Arsene E, Ispas AT, et al. Estimation of the age from fetal occipital bone. Rev Rom Anat Funct Clin Macro Microsc Antropol. 2019; 18(3): 165-168.

2. Bernard S, Loukas M, Rizk E, et al. The human occipital bone: review and update on its embryology and molecular development. Childs Nerv Syst. 2015; 31(12): 2217-2223, doi: 10.1007/s00381-015-2870-8, indexed in Pubmed: 26280629.

3. Chano T, Matsumoto K, Ishizawa M, et al. Analysis of the presence of osteocalcin, S-100 protein, and proliferating cell nuclear antigen in cells of various types of osteosarcomas. Eur J Histochem. 1996; 40(3): 189-198, indexed in Pubmed: 8922947.

4. Duarte WR, Shibata T, Takenaga K, et al. S100A4: a novel negative regulator of mineralization and osteoblast differentiation. J Bone Miner Res. 2003; 18(3): 493-501, doi: 10.1359/jbmr.2003.18.3.493, indexed in Pubmed: 12619934.

5. Grzonkowska M, Baumgart M, Badura M, et al. Morphometric study of the primary ossification center of the frontal squama in the human fetus. Surg Radiol Anat. 2020; 42(7): 733-740, doi: 10.1007/s00276-020-02425-7, indexed in Pubmed: 32025797.

6. Grzonkowska M, Baumgart M, Badura M, et al. Quantitative anatomy of the fused ossification center of the occipital squama in the human fetus. PLoS One. 2021; 16(2): e0247601, doi: 10.1371/journal.pone.0247601, indexed in Pubmed: 33621236.

7. Lee SK, Kim YS, Jo YA, et al. Prenatal development of cranial base in normal Korean fetuses. Anat Rec. 1996; 246(4): 524-534, doi: $10.1002 /(\mathrm{SICI}) 1097-$ 0185(199612)246:4<524::AID-AR11>3.0.CO;2-Q, indexed in Pubmed: 8955791.

8. Morimoto N, Ogihara N, Katayama K, et al. Three-dimensional ontogenetic shape changes in the human cranium during the fetal period. J Anat. 2008; 212(5): 627-635, doi: 10.1111/j.1469-7580.2008.00884.x, indexed in Pubmed: 18430090 .

9. Nemzek WR, Brodie HA, Hecht ST, et al. MR, CT, and plain film imaging of the developing skull base in fetal specimens. Am J Neuroradiol. 2000; 21(9): 1699-1706, indexed in Pubmed: 11039353.

10. Shapiro R, Robinson F. Embryogenesis of the human occipital bone. Am J Roentgenol. 1976; 126(5): 1063-1068, doi: 10.2214/ajr.126.5.1063, indexed in Pubmed: 178231.

11. Skrzat J, Mróz I, Jaworek JK, et al. A case of occipitalization in the human skull. Folia Morphol. 2010; 69(3): 134-137, indexed in Pubmed: 21154282.

12. Wysocki J, Bubrowski M, Szymański I. Developmental anomalies of the atlantooccipital region and their meaning for disturbances of hearing and balance (in Polish). Otorynolaryngologia. 2003; 2(2): 65-71.

13. Zhang $\mathrm{Q}$, Wang $\mathrm{H}$, Udagawa J, et al. Morphological and morphometric study on sphenoid and basioccipital ossification in normal human fetuses. Congenit Anom (Kyoto). 2011; 51(3): 138-148, doi: 10.1111/j.17414520.2011.00322.x, indexed in Pubmed: 21848997. 